\title{
Case Report \\ Congenital Tongue Base Cyst Presenting with Laryngeal Stridor in Youth: A Case Report
}

\author{
Zouheir Zaki, Naouar Ouattassi, and Noureddine Alami \\ ENT Head and Neck Surgery Department, Hassan II University Hospital, 30000 Road Sidi Hrazem, BP 1893 Fez, Morocco
}

Correspondence should be addressed to Zouheir Zaki, zakizouheir@yahoo.fr

Received 14 May 2012; Accepted 26 July 2012

Academic Editors: Y. Baba, K. Morshed, and M. S. Timms

Copyright () 2012 Zouheir Zaki et al. This is an open access article distributed under the Creative Commons Attribution License, which permits unrestricted use, distribution, and reproduction in any medium, provided the original work is properly cited.

Introduction. Tongue base cyst is an uncommon but potentially dangerous cause of stridor in neonates and infants. Case Presentation. We report a case of a 2-month-old Arabic male infant with a congenital tongue base cyst revealed by inspiratory stridor and recurrent respiratory distress. Diagnosis of cyst was suspected at endoscopy and confirmed by MRI imaging. The cyst was marsupialized with $\mathrm{CO}_{2}$ laser. One year later, the child remains asymptomatic without recurrence of the mass. Conclusion. Tongue base cysts should be considered in differential diagnosis in new borns with stridor, respiratory difficulties, or swallowing problems. Definitive therapy requires large marsupialization under general anesthesia.

\section{Introduction}

Congenital tongue base cysts are an uncommon cause of airway obstruction $[1,2]$. An approximate annual incidence of 1.82 per 100000 live births in an oriental population was reported [3]. A tongue base cyst may cause stridor or respiratory distress or be totally asymptomatic. When the cyst is suspected clinically, endoscopic laryngoscopy and CT or MRI are necessary for diagnosis. The large laser marsupialization has become the standard therapy by most otolaryngologists.

\section{Case Presentation}

A 2-month-old male infant of Arabic origin and average socioeconomic status living in an urban area with a history of recurrent respiratory distress was referred to pediatric emergency for inspiratory stridor and sever dyspnea. Clinical examination found an apyretic child with polypnea and features of respiratory collapse, so he was intubated and transferred to pediatric intensive care. Biological analysis showed normal complete blood values, with no inflammatory syndrome, also the chest X-ray was normal. The diagnosis of laryngomalacia was suspected. The endoscopic laryngobronchoscopy was performed and disclosed a normal appearing larynx with no major inspiratory collapsus. The digital tongue base palpation revealed a submucosal soft midline mass (Figure 1). MRI showed a cystic lesion of the tongue base that drove back the epiglottis (Figure 2). Under general anesthesia, large laser $\mathrm{CO}_{2}$ marsupialization was done. One year after surgery, the patient was in perfect health without any airway problems and had gained weight.

\section{Discussion}

In medical literature, a variety of terms have been used for tongue base cysts, such as epiglottic cyst, lingual cyst, vallecular cyst, or laryngeal cyst [1-8]. Two major hypotheses to explain the pathogenesis are that this cyst is a consequence of either ductal obstruction of mucus glands or an embryological malformation [2]. Histologically, the cyst contains respiratory epithelium with mucous glands, with an external lining of squamous epithelium [2-4]. Most affected infants have symptoms during the first week of life [5]. Clinical manifestations consist of various degrees of upper airway obstruction such as inspiratory stridor, chest retraction, apnea, cyanosis, and feeding difficulty. Stridor is the most common symptom [1-8]. About $60 \%$ of children with stridor have laryngeal obstruction such as laryngomalacia, vocal cord paralysis, subglottic stenosis, hemangioma, or laryngeal cysts; $25 \%$ have lesions in the upper airway, including choanal atresia, macroglossia, 


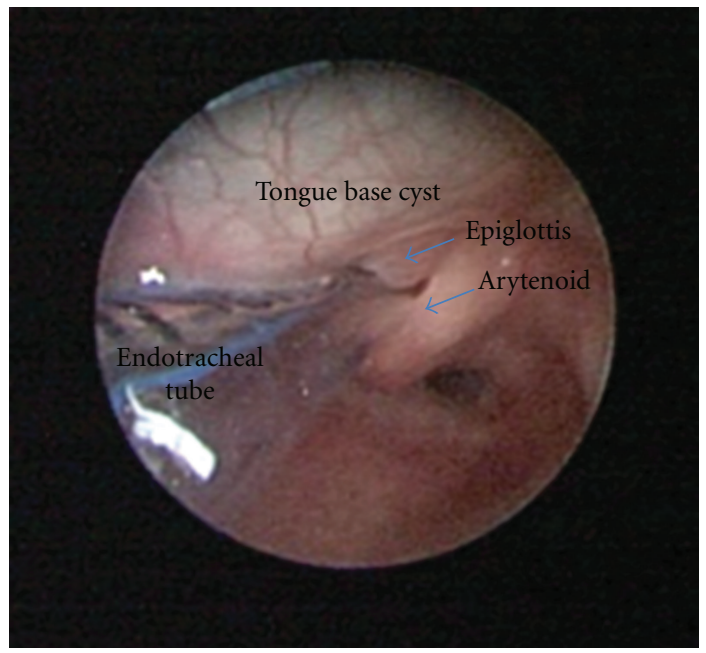

FIgURe 1: Endoscopic view showing the tongue base cyst and its contact with the larynx.

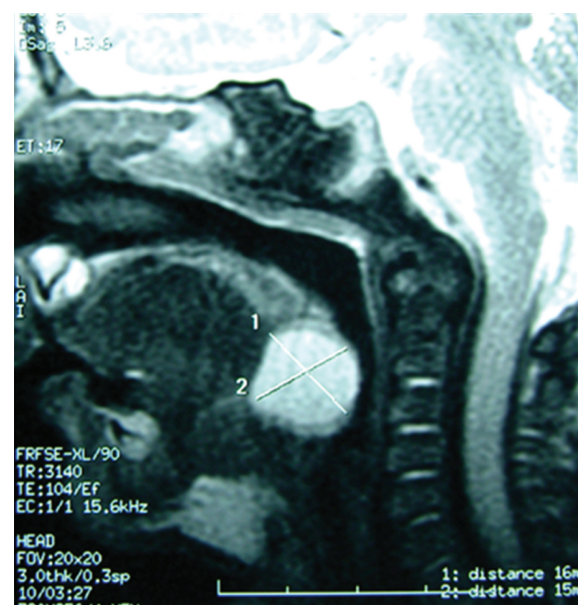

FIGURe 2: MRI in sagittal view shows a large cystic mass at the tongue base.

and/or facial anomalies; 15\% are due to tracheobronchial lesions such as tracheomalacia or vascular compression or other lesions [2]. In neonatal stridor, evaluation of the airway anatomy and differential diagnosis from other causes of stridor are important to prevent any mortality and morbidity from these sources. Lingual cysts are variable in size. If large, they can encroach upon the airway and displace the epiglottis, causing airway obstruction. Small cysts are totally asymptomatic. Finger palpation for a tongue base mass in children with stridor and swallowing disturbance is simple and may be the first clue to lingual cysts. However, finger palpation of the base of the tongue must be performed with great care and should be done in a controlled environment for emergency airway management. The palpation may sometimes cause rupture of the cyst [1-3]. In a young infant with respiratory stridor and dysphagia, which rapidly resolve after airway manipulations, spontaneous rupture of a tongue base cyst should be highly suspected and vigilant followup is necessary in case of recurrence [1]. Primary diagnostic approach to laryngeal or vallecular cysts should be a flexible nasopharyngeal laryngoscopy or bronchoscopy. CT and MR imaging often help narrow the differential diagnosis such as lingual thyroid, proximal cystic dilatation of the thyroglossal duct, lymphangioma or hemangioma, dermoid cyst, lipoma, fibroma, or carcinoma [6]. Although surgical removal may be the treatment of choice, other modalities such as endoscopic marsupialization, excision, and deroofing of the cyst have been recently developed. Marsupialization under general anesthesia is a safe and definitive procedure, especially when performed by $\mathrm{CO}_{2}$ laser. Sometimes, preintubation aspiration becomes necessary before the insertion of the endotracheal tube. Simple aspiration of the cyst is not advised because of its high recurrence rate [1-6]. Spontaneous disappearance of a tongue base cyst after oropharyngeal suctioning has not been previously reported [1-8]. In conclusion, tongue base cysts should be considered in differential diagnosis in new borns with stridor, respiratory difficulties, or swallowing problems. An endoscopic laryngobronchoscopy has to be performed before making the diagnosis of laryngomalacia. Definitive therapy requires large marsupialisation under general anesthesia.

\section{Consent}

The authors had obtained written informed consent from the patient's legal guardian for publication of this case report and accompanying images. A copy of the written consent is available for review by the Editor-in-Chief of this journal.

\section{Conflict of Interests}

The authors declare that they have no conflict of interests.

\section{Authors' Contribution}

Z. Zaki has performed the endoscopic diagnosis and treatment; also he has made substantial contributions to the acquisition of video data of the endoscopic procedure. N. Ouattassi has been involved in drafting the paper N. Alami has revised the paper critically for important intellectual content and has given final approval of the version to be published. All authors read and approved the final paper.

\section{References}

[1] K. S. Wong, Y. H. Huang, and C. T. Wu, "A vanishing tonguebase cyst," The Turkish Journal of Pediatrics, vol. 49, no. 4, pp. 451-452, 2007.

[2] M. A. Yang, M. J. Kang, J. N. Hong et al., "A case of congenital vallecular cyst associated with GER presenting with stridor, feeding cyanosis and failure to thrive," Korean Journal of Pediatrics, vol. 51, no. 7, pp. 775-779, 2008.

[3] B. Ahrens, I. Lammert, M. Schmitt, U. Wahn, K. Paul, and B. Niggemann, "Life-threatening vallecular cyst in a 3 month-old infant: case report and literature review," Clinical Pediatrics, vol. 43, no. 3, pp. 287-290, 2004. 
[4] W. S. Hsieh, P. H. Yang, K. S. Wong, H. Y. Li, E. C. R. Wang, and T. F. Yeh, "Vallecular cyst: an uncommon cause of stridor in newborn infants," European Journal of Pediatrics, vol. 159, no. 1-2, pp. 79-81, 2000.

[5] N. B. Sands, S. M. Anand, and J. J. Manoukian, "Series of congenital vallecular cysts: a rare yet potentially fatal cause of upper airway obstruction and failure to thrive in the newborn," Journal of Otolaryngology, vol. 38, no. 1, pp. 6-10, 2009.

[6] P. S. Chung, Y. W. Chung, S. J. Park et al., "A clinicopathologic study of epiglottic and vallecular cysts," Korean Journal of Otorhinolaryngology, vol. 47, pp. 157-160, 2004.

[7] T. C. Yao, C. Y. Chiu, K. C. Wu, L. J. Wu, and J. L. Huang, "Failure to thrive caused by the coexistence of vallecular cyst, laryngomalacia and gastroesophageal reflux in an infant," International Journal of Pediatric Otorhinolaryngology, vol. 68, no. 11, pp. 1459-1464, 2004.

[8] P. G. C. Gluckman, T. W. F. Chu, and C. A. Van Hasselt, "Neonatal vallecular cysts and failure to thrive," Journal of Laryngology and Otology, vol. 106, no. 5, pp. 448-449, 1992. 


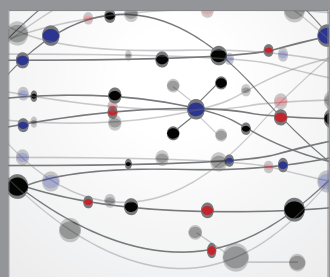

The Scientific World Journal
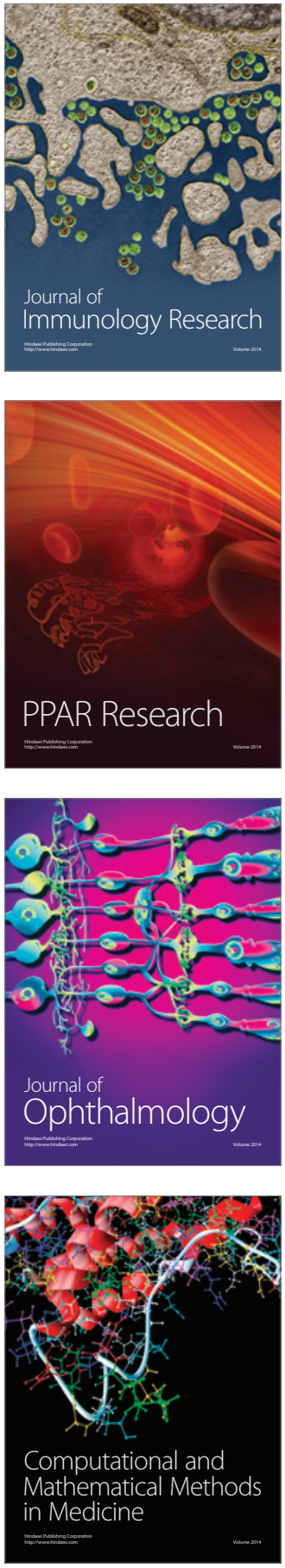

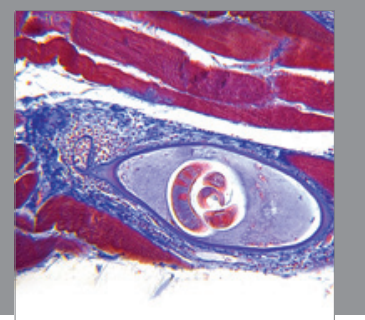

Gastroenterology

Research and Practice
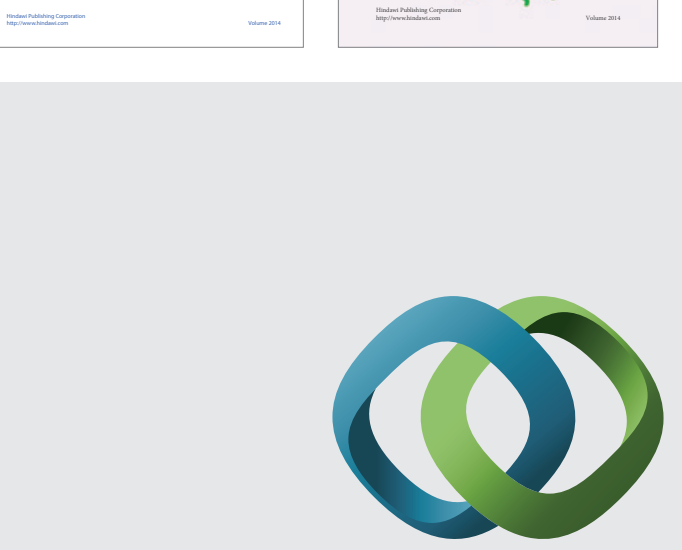

\section{Hindawi}

Submit your manuscripts at

http://www.hindawi.com
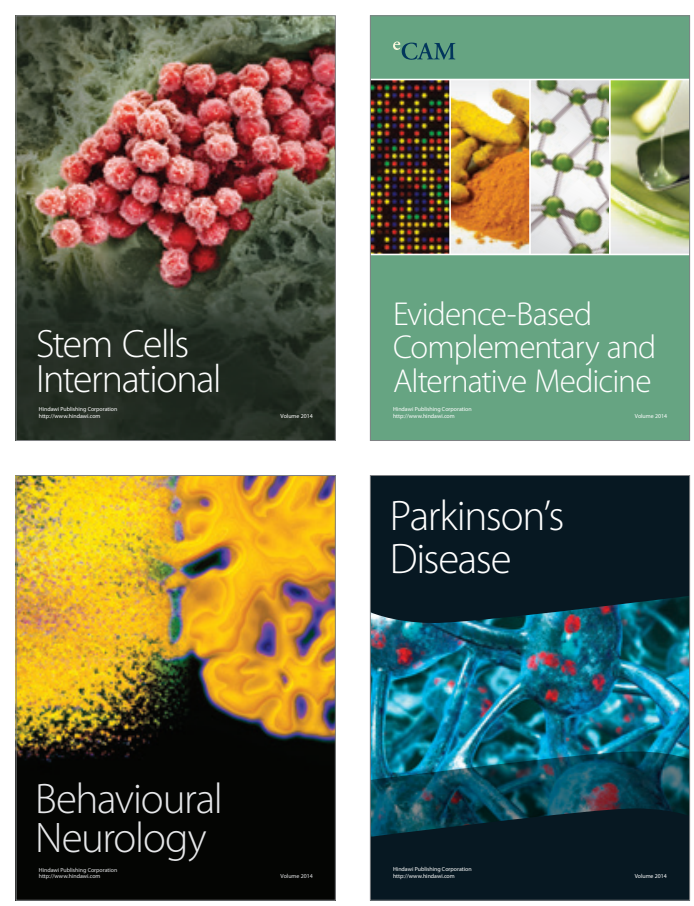



Journal of
Diabetes Research

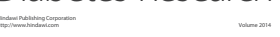

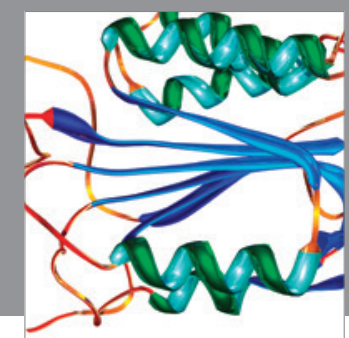

Disease Markers
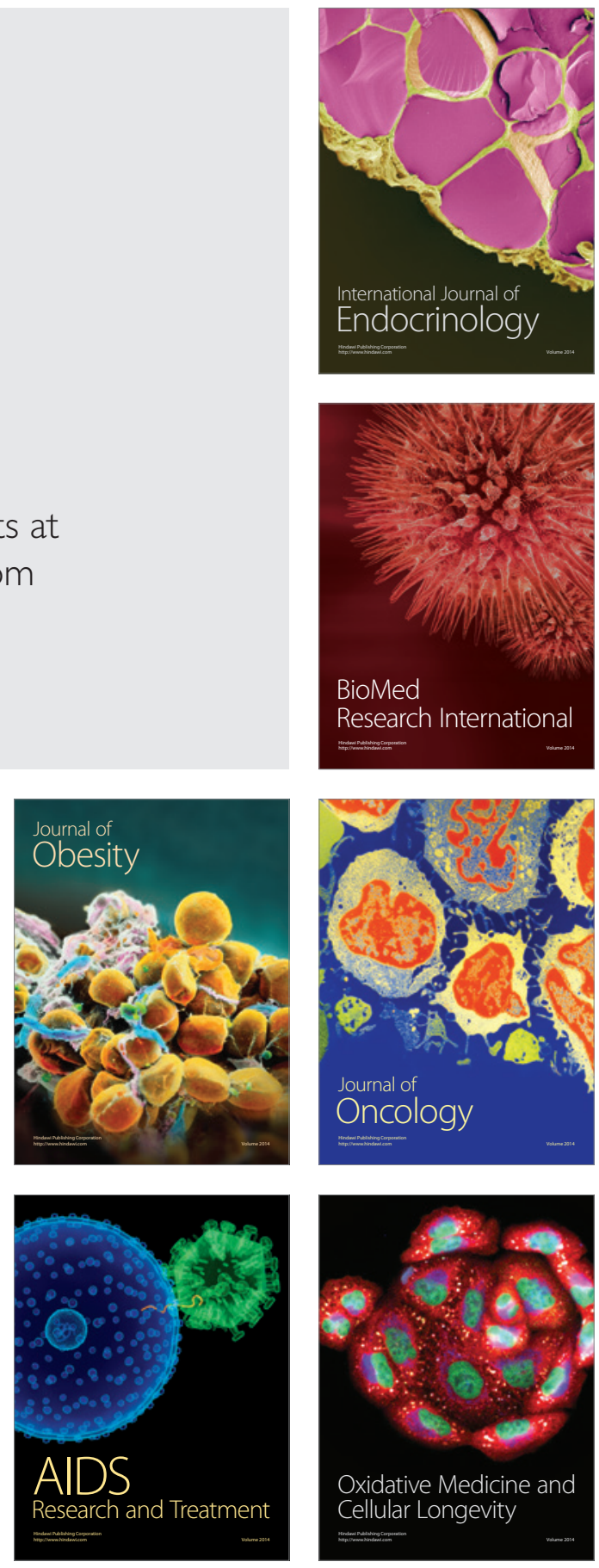